\title{
AKTIEWE DIENS IN SUIDER-AFRIKA
}

'n Omvattende reorganisasie van die Suid-Afrikaanse Weermag in die vroeë sestigerjare het onder meer voorsiening gemaak vir die skep van ses veggroepe met die oog op onkonvensionele oorlogvoering. Hierdie soort oorlogvoering het in Suider-Afrika gestalte gekry in toenemende terroristebedrywighede in Suidwes-Afrika, Angola, Mosambiek en elders.

In 1974 het die Portugese bewind in Mosambiek en Angola ineengestort en gedurende die Angolese Burgeroorlog (1975-1976) het 'n Suid-Afrikaanse taakmag in die suide van Angola opgetree ten einde te verhoed dat die oorlog na SWA uitbrei.

Die Suid-Afrikaanse taakmag van slegs sowat 2000 man het te staan gekom teen 'n groot oormag van Kubaanse en MPLA-magte wat op die logistieke ondersteuning van die Sowjet-Unie kon staatmaak. Desondanks het die Suid-Afrikaanse veggroepe skitterende oorwinnings behaal. So byvoorbeeld het Taakmag Zulu in 'n Blitzkrieg die suidwestelike hoek van Angola herverower nadat verskeie dorpe ingeneem is, onder andere Pereira de Eca, Rocadas, Humpata en Mocamedes.

In Sentraal-Angola het veggroep Foxbat op 26 Oktober 1975 die vyand by Liumbala 'n verpletterende nederlaag toegedien. Hierna het taakmag Zulu tot die stryd toegetree en verdere oorwinnings is behaal by Cacula en Catengue. Die SuidAfrikaners se oorwinning by Catengue op 5 November het die vyand dermate gedemoraliseer dat dit die Benguela-front ontruim en van sy beplande offensief na die suide afgesien het.

Aan die Cela-front het die Suid-Afrikaanse magte, bestaande uit Vegspan Zulu en Veggroep Foxbat die vyand in die Santa Comba-gebied gestuit en 'n oorwinning in die slag van Ebo behaal. In die ooste van Angola het Veggroep X-Ray ook klinkende oorwinnings by Cangongo en Luso behaal.

Die Suid-Afrikaners se oorwinning in die slag van Brug 14 is wel bekend. Nadat die vyandelike aan- val afgeweer is, het Foxbat en Zulu 'n teenoffensief geloods en Cassamba en Almeida beveilig. Hiermee was die Suid-Afrikaanse deelname aan die Angolese konflik feitlik afgeloop en op 15 Januarie 1976 is die finale onttrekkingsbevel uitgereik. Die onttrekking van die Suid-Afrikaanse magte aan Angola (wat nie die gevolg was van enige militêre nederlae wat gely is nie) het stelselmatig en ordelik geskied.

Sedert die onttrekking van die Suid-Afrikaanse magte uit Angola in 1976 kon SWAPO-terroriste vanaf hul basisse in Suid-Angola 'n veldtog van terreur in Suidwes-Afrika loods. Dit het die SuidAfrikaanse Weermag genoop om sy teenwoordigheid in Suidwes-Afrika te vestig en die gebied te beveilig.

Sedert Mei 1978, toe twee groot terroristebasisse in Angola tydens Operasie Reindeer vernietig is, het die Suid-Afrikaanse veiligheidsmagte in samewerking met die plaaslike SWA Gebiedsmag verskeie voorsprong- en opvolgoperasies met welslae onderneem, onder andere Sceptic (1980), Protea (1981), Daisy (1981), Super (1982) en Askari (1983).

Operasie Protea was die grootste gemeganiseerde krygsoperasie deur die Suid-Afrikaanse Weermag sedert die Tweede Wêreldoorlog. Dit het twee maande geduur. Groot hoeveelhede gesofistikeerde wapentuig is gebuit of vernietig en SWAPO se totale logistieke stelsel in Suid-Angola is vernietig. Gedurende Operasie Askari is ook groot hoeveelhede wapens gebuit, insluitende die nuwe Russiese AGS 17 granaatwerper en 'n volledige SA9 lugafweermissiel.

Sedert 1975, toe terroristegroepe vanuit buurstate in die RSA begin optree het, het elemente van die Suid-Afrikaanse Weermag by verskillende geleenthede langs die RSA se grens slaags geraak met terroriste wat die land probeer binnekom het. Binnelands speel die Suid-Afrikaanse Weermag ook 'n belangrike rol in die bekamping van terrorisme en die handhawing van wet en orde. 


\section{ACTIVE SERVICE IN SOUTHERN AFRICA}

A comprehensive reorganisation of the South African Defence Force in the early sixties amongst others, made provision for the establishment of six combat groups with a view to unconventional warfare. This type of warfare resulted from increasing terrorist activities in South West Africa, Angola, Mosambique and elsewhere.

Portuguese rule in Mosambique and Angola ended in 1974 and during the Angolan Civil War (1975-1976) a South African task force was deployed in Southern Angola in order to prevent the war from spreading to SWA.

A South African task force of only 2000 men faced a superior force of Cuban and MPLA forces which could reply on the logistic support of the Soviet Union. The South African combat groups nevertheless gained some splendid victories. For example Task Force Zulu recaptured the south-western corner of Angola in a Blitzkrieg after several towns had been captured, inter alia Pereira de Eca, Rocadas, Humpata and Mocamedes.

On 26 October 1975 the enemy suffered a crushing defeat at the hands of Combat Group Foxbat at Luimbala. After this, Task Force Zulu joined the battle and further victories were gained at Calcula and Catengue. The South Africans' victory at Catengue on 5 November demoralised the enemy to such an extent that the Benguela Front was evacuated and the enemy abandoned its planned offensive to the south.

At the Cela Front the South African forces, comprising Combat Team Zulu and Combat Team Foxbat, checked the enemy in the Santa Comba area and gained a victory in the Battle of Ebo. Combat Group X-Ray gained overwhelming victories at Cangongo and Luso.

The South Africans' victory in the Battle of Bridge 14 is well-known. After the enemy attack was warded off, Foxbat and Zulu launched a counter-offensive and secured Cassamba and Almeida. With this South Africa's participation in the Angolan conflict was more or less terminated and the final evacuation order was issued on 15 January 1976. The evacuation of the South African forces from Angola (which was not the result of any military defeats) was effected in a systematic and orderly fashion.

Since the evacuation of the South African forces from Angola in 1976, SWAPO terrorists have been able to launch a terror campaign in South West Africa from their bases in Angola. This has compelled the South African Defence Force to establish its presence in South West Africa and to safeguard this region.

Since May 1978, when two large terrorist bases in Angola were destroyed during Operation Reindeer, the South African Security Forces, in collaboration with the local SWA Territorial Force, successfully conducted several pre-emptive and follow-up operations, amongst others Sceptic (1980), Protea (1981), Daisy (1981), Super (1982) and Askari (1983)

Operation Protea was the largest mechanised war operation by the South African Defence Force since World War II. It lasted for two months. Large quantities of sophisticated weapons were seized or destroyed and SWAPO's entire logistics system in Southern Angola was destroyed. A large number of weapons were also seized, including the new Russian AGS 17 grenade launcher and a complete SA 9 anti-aircraft missile.

Since 1975, when terrorist groups began to act in the RSA from neighbouring countries, elements of the South African Air Force have experienced several contacts along the RSA's borders with terrorists attempting to infiltrate the country. The South African Defence Force also plays an important role in the internal fight against terrorism and in maintaining law and order. 


\section{SERVICE ACTIF EN AFRIQUE AUSTRALE}

Le début des années soixante vit une réorganisation complète de l'armée sud-africaine, avec entre autres, la création de six groupements tactiques spécialisés dans la guerre non-conventionelle. La menace que ce genre de conflit représentait devenait plus pressante en raison de l'accroissement des activités terroristes au Sud-Ouest Africain, en Angola au Mozambique et ailleurs dans la région.

1974 vit la chute de gouvernement portugais au Mozambique et en Angola et, au cours des années 75 et 76, l'Angola fut plongé dans la guerre civile. Les Sud-Africains décidèrent alors d'envoyer un corps expéditionnaire dans le sud angolais afin d'éviter que la guerre ne se propage au Sud-Ouest Africain.

La force d'intervention tactique sud-africaine, qui ne comptait que quelques 2000 hommes, dût bientôt affronter les Cubains et les forces du MPLA dont les effectifds étaient beaucoup plus importants et qui bénéficiaient du soutien logistique de l'Union Sovietique. Les groupements de combat sud-africains obtinrent néamoins de brillants succès: le groupement Zulu reconquit la partie sud-ouest de l'Angola dans une veritable guerre éclair au cours de laquelle ils s'emparèrent de plusieurs villes parmi lesquelles Pereira de Eca, Rocadas, Humpata et Mocamedes.

Le 26 octobre 1975, le groupement de combat Foxbat, infligea une défaite cuisante à l'ennemi à Luimbala, au centre de l'Angola. Le groupement Zulu entra bientôt dans la bataille et de nouvelles victoires s'ensuivirent à Cacula et Catengue. $\mathrm{La}$ victoire des Sud-Africains à Catengue le 5 novembre démoralisa l;ennemi á tel point qu'il abandonna le front de Benguela et renonca à son offensive vers le sud.

Sur le front de Cela, les Forces Sud-Africaines composées des deux groupements tactiques Zulu et Foxbat arrêtèrent l'ennemi dans la région de Santa Comba et furent victorieuses à Ebo. Dans l'est de l'Angola le groupement tactique X-Ray obtint également des victoires retentissantes à Cancongo et Luso.

La victoire sud-africaine à la bataille de Bridge 14 est célèbre: après avoir repoussé l'attaque ennemi,
Foxbat et Zulu lancèrent une contre-offensive au cours de laquelle ils s'emparèrent de Cassamba et Almeida. Cet épisode mit le point final à la participation sud-africaine dans le conflit angolais: le 15 janvier 1976 les Forces sud-africaines recurent l'ordre d'évacuer l'Angola, repli qui s'effectua dans la méthode et l'ordre. Il convient de préciser que l'Afrique du Sud choisit alors d'évacuer ses troupes de son plein gré et nullement en raison d'une défaite militaire.

En mai 1978 deux bases terroristes importantes situées sur le territoire angolais, furent détruites par les sud-africains au cours de l'opération Reindeer. Depuis les Forces sud-africaines ont lancé plusieurs opérations de poursuite immédiate en collaboration avec les forces régionales du Sud-ouest Africain. Ces opérations comme Sceptic en 1980, Protea et Daisy en 1981, Super en 1982 et Askari en 1983, ont toutes été couronnées de succés.

Après le retrait des troupes sud-africains d'Angola en 1976, les terroristes de la SWAPO ont pu utiliser leurs bases du sud-angolais pour lancer une campagne de terreur au sud-ouest africain. L'armée sud-africaine s'est donc vue obligée d'établir sa présence sur le terrotoire afin de le protéger.

L'opération Protea fut l'opération motorisée la plus importante lancée par les forces sud-africaines depuis la deuxième guerre mondiale. Au cours des deux mois que dura cette opération, des quantités importantes d'armement sophistiqué furent saisies ou détruites et tout le système logistique de la SWAPO dans le sud-angolais fut démemtelé. Au cours de l'operation Asakri, un grand nombre d'armes fut également saisi, en particulier un nouveau lanceur de grenades sovietique AGS 17 et un missile anti-aerien, SA 9.

Depuis 1975, des groupes terroristes basés dans les pays voisins ont commencé leur action contre la République d'Afrique du Sud et pïusieurs accrochages se sont produits aux frontières entre les forces de l'prdre sud-africaines et les terroristes qui tentaient de s'infiltrer dans le pays. L'armée SudAfricaine joue également un rôle important à l'intérieur du pays où elle est chargée de la lutte antiterroriste et du maintien de l'ordre. 


\section{KAMPFTÄTIGKEITEN IM SÜDLICHEN AFRIKA}

Die umfassende Neugliederung der südafrikanischen Wehrmacht am Anfang der sechziger Jahre sah sechs Gefechtesgruppen für unkonventionelle Kriegsführung vor. Diese Art der Kriegsführung kam in zunehmenden Terroristenaktivitäten in Südwestafrika, Angola, Mosambik und anderswo zum Ausdruck.

1974 brach die portugiesische Regierungin Mosambik und Angola zusammen. Während des Bürgerkrieges in Angola (1975-1976), wurde eine südafrikanische Kampfgruppe im Süden Angolas eingesetzt. Ihre Aufgabe war es um vorzubeugen, dass sich der Krieg nach Südwestafrika ausbreitete.

Die südafrikanische Kampfgruppe von nur ca. 2000 Mann stand den kubanischen und MPLAMächten, die ihnen zahlenmässig bei weitem überlegen waren, gegenüber. Letztere hatten die logistische Unterstützung der Sowjetunion. Trotzdem errangen die südafrikanischen Gefechtsgruppen glänzende Siege. So zum Beispiel eroberte die Gefechtsgruppe Zulu während eines Blitzkrieges die südwestliche Ecke Angolas nachdem sie bereits andere Dörfer erobert hatten, u.a. Pereira de Eca, Rocado, Humpata und Mocamedes.

In Zentral-Angola fügte die Gefechtsgruppe Foxbat am 25. Oktober 1975 dem Feind bei Luimbala eine zerschmetternde Niederlage zu. Dann trat die Gefechtsgruppe Zulu in den Kampf ein und errang weitere Siege bei Cacula und Catengue. Der Sieg der Südafrikaner bei Catengue am 5 . November hatte den Feind dermassen zermürbt, dass er die Benguela-Front räumte und auf seine beabsichtigte Offensive nach dem Süden verzichtete.

An der Cela-front wurde dem Feind bei Santa Comba von den südafrikanischen Mächten, die aus den beiden Gefechtsgruppen Zulu und Foxbat zusammengesetzt worden waren, Einhalt geboten. Die Südafrikaner errangen den Sieg in der Schlacht von Ebo. Im Osten Angolas siegten die Gefechtsgruppen "X-Ray" auch auf glänzende Weise bei Cangongo und Luso.

Der Sieg der Südafrikaner in der Schlacht von "Bridge 14" ist wohlbekannt. Nachdem sie den feindlichen Angriff abgewehrt hatten, unternahmen Foxbat und Zulu einen Gegenangriff und sicherten Cassamba und Almeida. Damit war die südafrikanische Teilnahme am angolesischen Konflikt fast zu Ende gekommen und am 15. Januar 1976 wurde der endgültige Rückzugsbefehl gegeben. Der Rückzug der südafrikanischen Mächte aus Angola, der nicht wegen irgendwelcher militärischen Niederlagen stattfand, ging planmässig und ordentlich vor sich.

Seit obenerwähntem Rückzug 1976 ist es den SWAPO-Terroristen möglich, von ihren Stützpunkten in Südangola aus, Terrortaten in Südwestafrika zu begehen. Zum Schutz des Gebietes wurde die südwestafrikanische Wehrmacht in Südwestafrika eingesetzt.

Seit Mai 1978, als zwei grosse Terroristenstützpunkte in Angola während "Operation Reindeer" vernichtet worden waren, unternahmen die südafrikanischen Sicherheitmächte in Zusammenarbeit mit den örtlichen südwestafrikanischen Truppen verschiedene erfolgreiche Vorsprungund Nachfolge-Einsätze, u.a. Sceptic (1980), Protea (1981), Daisy (1981), Super (1982) und Askari (1983).

"Operation Protea" war der grösseste mechanisierte Kriegseinsatz der südafrikanischen Wehrmacht seit dem Zweiten Weltkrieg. Dieser dauerte zwei Monate. Grosse Mengen modernes feindliches Kriegsgerät wurden erbeutet oder vernichtet. SWAPO's ganzes logistisches System in Südangola wurde vernichtet. Während "Operation Askari" wurden grosse Mengen Waffen erbeutet, einschliesslich des neuen russischen AGS-17-Granatwerfers und eines vollständigen SA-9-Luftabwehrflugkörpers.

Seit 1975, als Terroristengnuppen von Nachbarländern in der Republik Südafrika aktiv wurden, stiessen Teile der südafrikanischen Wehrmacht verschiedene Male an der südafrikanischen Grenze mit Terroristen zusammen, welche versuchten, in das Land einzudringen. Im Inneren spielt die südafrikanische Wehrmacht eine wichtige Rolle im Kampf gegen den Terrorismus und leistet Hilfe in der Aufrechterhaltung des Gesetzes und der guten Ordnung. 